\title{
Dermoscopic changes in melanocytic nevi covered with both opaque tape and sunscreen cream during narrowband ultraviolet B therapy
}

\author{
Derya Ök Kekeç ${ }^{1}$ Nida Kaçar², Işıl Kılınç Karaarslan³
}

1 Denizli Public Hospital, Denizli, Turkey

2 Department of Dermatology, Pamukkale University, Denizli, Turkey

3 Department of Dermatology, Ege University, Izmir, Turkey

Key words: dermoscopy, sunscreen, melanocytic nevus, phototherapy, narrowband ultraviolet B

Citation: Ök Kekeç D, Kaçar N, Kilinç Karaarslan I. Dermoscopic changes in melanocytic nevi covered with both opaque tape and sunscreen cream during narrowband ultraviolet B therapy. Dermatol Pract Concept. 2018;8(2):132-139. DOI: https://doi.org/10.5826/ dpc.0802a13

Received: January 25, 2018; Accepted: February 20, 2018; Published: April 30, 2018

Copyright: $@ 2018$ Ök Kekeç et al. This is an open-access article distributed under the terms of the Creative Commons Attribution License, which permits unrestricted use, distribution, and reproduction in any medium, provided the original author and source are credited.

Funding: This study was financially supported by grant number 2015TPF011 from the Scientific Research Projects Foundation of Pamukkale University.

Competing interests: The authors have no conflicts of interest to disclose.

All authors have contributed significantly to this publication.

Corresponding author: Nida Kaçar, MD, Pamukkale Universitesi Tip Fakultesi, Dermatoloji Anabilim Dali, Kırmızı Bina, 3. Kat Kinikli, 20070 Pamukkale Denizli, Turkey. Tel.+902582965875. Email: n_gelincik@yahoo.com

ABSTRACT Background: Ultraviolet (UV) light may cause dermoscopic changes on melanocytic nevi (MN).

Objectives: To investigate the effects of sunscreen cream (SSc) application on dermoscopic changes in MN during narrowband UVB (NBUVB) therapy.

Methods: Half of the randomly selected MN in each patient were covered with opaque tape and SSc $[\mathrm{SSc}(+)]$, and the rest were covered with only opaque tape [SSc(-)] during NBUVB treatment sessions.

Results: More SSc(-) MN displayed dermoscopic changes at end of NBUVB therapy compared to the start of therapy $(\mathrm{p}=0.035)$. The number of the $\mathrm{MN}$ that decreased in size and showed loss of structure was significantly higher in SSc(-) $\mathrm{MN}$ ( $\mathrm{p}=0.04$ and $\mathrm{p}=0.026$, respectively).

Conclusions: Sunscreen in combination with opaque tape may contribute to some dermoscopic changes in melanocytic nevi, including decrease in size and loss of structure.

\section{Introduction}

Phototherapy is an effective treatment method for many skin diseases. The most important chronic side effect of phototherapy is carcinogenesis. According to the information available, although the carcinogenetic effects of narrowband ultraviolet $\mathrm{B}$ (NBUVB) treatment seems more moderate when compared to other forms of phototherapy, its long-term reliability is not known exactly [1].

Dermoscopy is among the optical techniques with higher efficacy in the earlier diagnosis of skin cancer compared to naked-eye examination [2]. For this reason, total body examinations, both clinical and dermoscopic, are being performed in many centers before and during phototherapy. 
UV light can cause clinical, histopathologic and dermoscopic changes in melanocytic nevi (MN) [3-5]. The dermoscopic changes observed in MN after NBUVB or ultraviolet A1 (UVA1) exposure did not occur in MN covered with opaque tape or sunscreen cream (SSc). In the direction of these findings, it was suggested that the dermoscopic changes induced by UVA1 and ultraviolet B (UVB) can be prevented successfully with either opaque tape or highly protective factor SSc; however, no significant histologic and immunohistochemical changes were detected in $\mathrm{MN}$ showing dermoscopic changes [6]. Although dermoscopic changes were recorded in a significantly few amount of covered MN during phototherapy sessions, they still occured in a noteworthy part of the covered $\mathrm{MN}$ [5,7,9]. The Turkish Dermatology Society Phototherapy Guidelines advise covering big and atypical $\mathrm{MN}$ and premalignant lesions before phototherapy [9].

Based on the above findings, we covered half of the selected MN with opaque tape and SSc and the rest with only opaque tape during all phototherapy sessions in order to investigate whether the use of SSc in addition to opaque tape has an additive effect in preventing dermoscopic changes induced by UV exposure. We also evaluated the development of new MN during follow-up. As far as we know, our study is the first study searching dermoscopic changes in covered MN with both opaque tape and SSc and new MN development during phototherapy.

\section{Materials and Methods}

All patients with a variety of dermatologic diseases were refered to our phototherapy unit for NBUVB therapy between January 28, 2015 and July 25, 2016 were evaluated in terms of eligibility for the study. The patients who were older than 1 year old and had at least two $\mathrm{MN}>2 \mathrm{~mm}$ size located on body and/or proximal extremity without melanoma suspicion were invited to participate in the study. Exclusion criteria included personal or family history of melanoma or cutaneous malignant epithelial tumor, active infection, atypical mole syndrome, active or previous history of systemic inflammatory or neoplastic disease, immunosuppressive medication, phototherapy history, and artificial UV exposure. MN located on sun-exposed body parts such as the head, neck, and distal extremities were not taken into consideration.

Every study participant signed an Informed Consent Form. Phototherapy was given using a Waldman UV 7001K (TL-01) device equipped with F85/100W-01 (TL01) Philips fluorescent tubes. At least two $\mathrm{MN}$ sized $>2 \mathrm{~mm}$ were selected randomly in each patient. Half of the selected $\mathrm{MN}$ in each patient were covered with opaque tape after SSc application $\mathrm{SSc}(+)$, and the rest were covered only with opaque tape-without SSc application SSc(-). SSc was applied approximately 20 minutes before the opaque tape was applied. SPF $50+$ SSc containing organic and inorganic filters against UVA-UVB (Solante; Buergli Pharma, Inc., Makati, Philippines) was used. Dermoscopic images of the selected MN were captured with a digital dermoscopy system at the beginning, at the end, and 3-6 months after the end of NBUVB therapy. At all follow-ups, total body mole mapping was performed with a fully automated body mole-mapping programme (Body Studio ATBM; FotoFinder Systems Inc, Columbia, MD, USA). Dermoscopic photographing, total body mole mapping, and arrangement of photographs were performed by one researcher (DÖK). The evaluation of the images was done by another researcher $(\mathrm{NK})$ without knowing whether the lesion was SSc(+) or SSc(-). The MN that showed unexpected dermoscopic findings, such as decrease in size or loss of structure, were further evaluated by another researcher (IKK).

The data were analyzed with the SPSS Statistics 21 packet programme. Sustained variables were given as average \pm standard deviation, minimum - maximum assets and categorical variables for numbers and percentages. In order to compare the independent group discrepancies, the Mann-Whitney U test was used. The differences between categoric variables were examined with Chi-square test. For examination of risk factors, the logistic regression test was used.

\section{Results}

Of the 24 patients enrolled, a total of $165 \mathrm{MN}$ were identified. Excluded from the study were 6 patients with $34 \mathrm{MN}$, who were lost to follow-up and $11 \mathrm{MN}$ of included patients that had poor image quality. In sum, the study included $120 \mathrm{MN}$ belonging to 18 patients (mean age: $44.7 \pm 14.2$ years; 13 women).

The majority of patients were diagnosed with mycosis fungoides $(\mathrm{n}: 5 ; 27.8 \%)$ and psoriasis $(\mathrm{n}: 5 ; 27.8 \%)$; the remaining diagnoses were pruritus, granuloma annulare, pityriasis lichenoides chronica and perforating dermatoses. Fitzpatrick skin type 3 was the most common skin type (n:14; 77.8\%). The mean cumulative treatment dose was $32.9 \pm 33.3$ joule/ $\mathrm{cm}^{2}$ (range 1.53-100.14 joule/ $\mathrm{cm}^{2}$ ). One patient received acitretin treatment in addition to phototherapy. Forty-two $\mathrm{MN}$ [18 SSc(+); $24 \mathrm{SSc}(-)$ ] were reexamined after a mean of 4.2 \pm 1.2 months (range: 3-6 months) after the end of NBUVB therapy. SSc(-) and SSc(+) groups constituted 68 $(56.7 \%)$ and $52(43.3 \%)$ patients, respectively.

The most frequently observed dermoscopic pattern was reticular pattern $(\mathrm{n}=50 ; 41 \%)$, followed by homogenousreticular pattern $(\mathrm{n}=31 ; 25.8 \%)$, homogenous pattern $(\mathrm{n}=17$; $14.2 \%)$, globular pattern $(\mathrm{n}=12 ; 10.0 \%)$, homogenousglobular pattern $(n=8 ; 6.7 \%)$, and multicomponent pattern 
TABLE 1. MN showing dermoscopic changes at the beginning, at the end, and 3-6 months after end of therapy

\begin{tabular}{|l|c|c|c|} 
& Beginning vs. end & $\begin{array}{c}\text { End vs. 3-6 months } \\
\text { after the end }\end{array}$ & $\begin{array}{c}\text { End vs. 3-6 months } \\
\text { after the end }\end{array}$ \\
\hline $\mathrm{SSc}(+) ; \mathrm{n}(\%)$ & $19(15.8 \%)$ & $6(14.2 \%)$ & $6(14.2 \%)$ \\
\hline $\mathrm{SSc}(-) ; \mathrm{n}(\%)$ & $38(31.6 \%)$ & $6(14.2 \%)$ & $3(7.1 \%)$ \\
\hline P value & $=0.035$ & $>0.05$ & $>0.05$ \\
\hline Total $\mathrm{n}(\%)$ & $57(47.5 \%)$ & $12(28.5 \%) *$ & $9(21.4 \%)^{*}$ \\
\hline
\end{tabular}

${ }^{\star}$ These ratios were calculated within $42 \mathrm{MN}$ that were reexamined after discontinuing therapy.

$(\mathrm{n}=2 ; 1.7 \%)$. Seventy percent of $\mathrm{MN}$ were located on the body, $25.8 \%$ on the arms, and $4.2 \%$ on the legs.

New MN development was not established during the study. Although the ratio of SSc(-) MN displaying dermoscopic changes was higher than $\mathrm{SSc}(+) \mathrm{MN}$ at the end of NBUVB therapy compared to the beginning; the ratio of $\mathrm{MN}$ displaying dermoscopic changes was similar in both SSc(-) and SSc(+) groups 3-6 months after the end of NBUVB therapy compared to the beginning and the end of therapy (Table 1).

No differences in dermoscopic changes according to anatomic locations were detected between $\mathrm{SSc}(-)$ and $\mathrm{SSc}(+)$ groups ( $\mathrm{p}>0.05)$.

Dermoscopic changes at the end of NBUVB therapy compared to the of therapy: The ratios of SSc(-) MN that showed decrease in size and loss of structure were higher than SSc(+) $\mathrm{MN}$ ( $\mathrm{p}=0.04$ and $\mathrm{p}=0.026$, respectively) (Figure 1). Failure to apply SSc over $\mathrm{MN}$ increased the ratio of decrease in size 4,681 times compared to $\mathrm{MN}$ applied with SSC $(\operatorname{Exp}(B): 4.681)$. The ratio of loss of structure was found to be increased 5.932 times in SSc(-) MN compared to $\mathrm{SSc}(+) \mathrm{MN}(\operatorname{Exp}(\mathrm{B}): 5.932)$. The mean exposed joules were comparable between the $\mathrm{SSc}(-)$ and $\mathrm{SSc}(+)$ $\mathrm{MN}$ showing decrease in size and loss of structure ( $\mathrm{p}>0.05)$. More SSc(-) MN showed fading in pigmentation, fading in pigment network, new structure and/ or color development, and increase in the number of dot and/or globules than

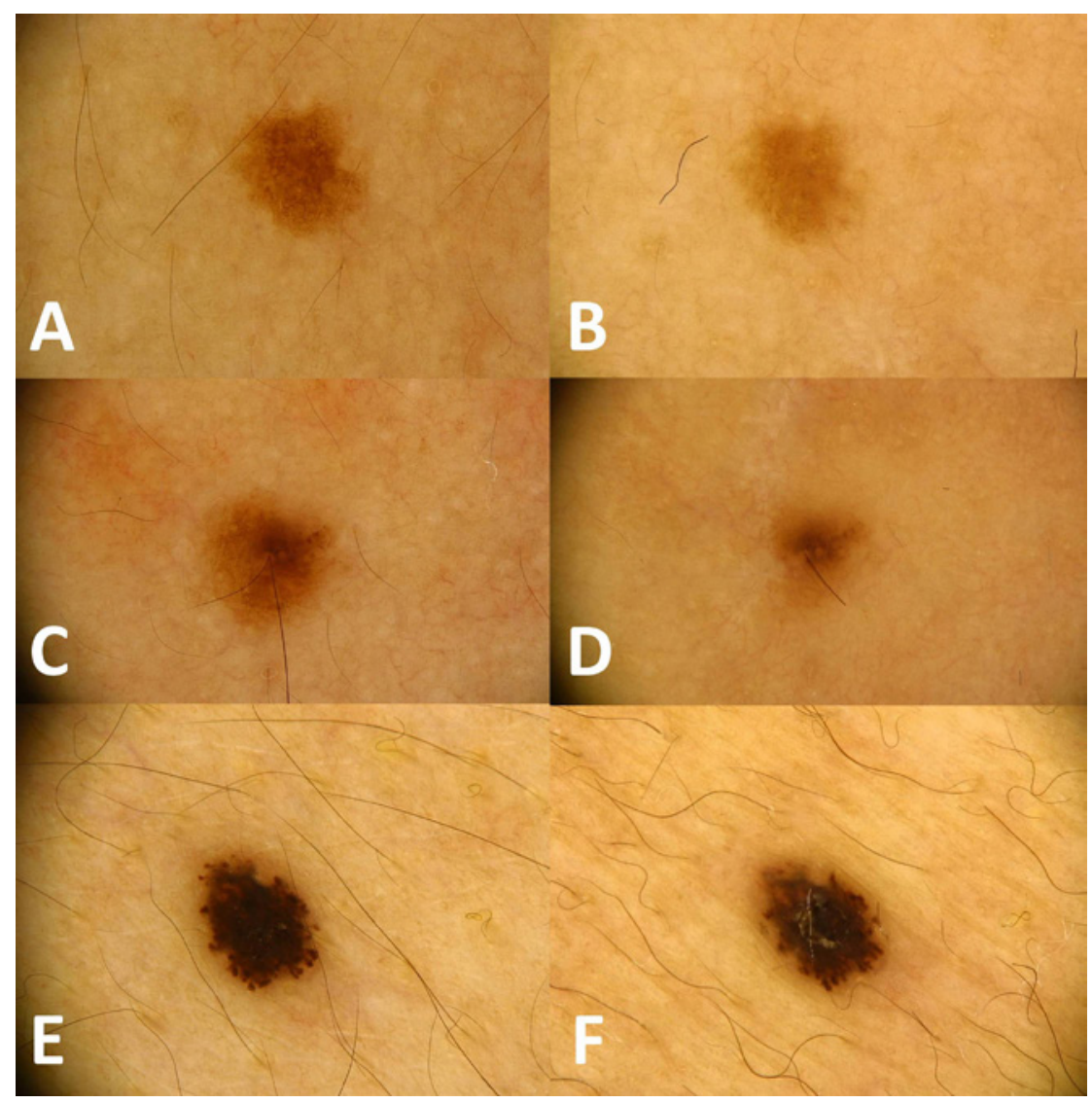

Figure 1. The nevi that showed fading in pigmentation and pigment network (B); fading in pigmentation together with decrease in size (D), and decrease in dots/globules together with increase in streaks and blue-gray color formation $(\mathrm{F})$ at the end of therapy compared to the beginning (A, C and E, respectively). [Copyright: @2018 Ök Kekeç et al.]

$\mathrm{SSc}(+) \mathrm{MN}$; but not at a significant level ( $>>0.05)$ (Table 2).

The ratio of $\mathrm{SSc}(+) \mathrm{MN}$ that showed darkening pigmentation, darkening pigment network, increase in size, and decrease in the number of dot and/or globules were higher than SSc(-) MN ( $>>0.05$ ) (Table 3).

The dermoscopic changes 3-6 months after the end of NBUVB therapy compared to the beginning and the end of therapy: These analyses were performed in SSc(-) $24 \mathrm{MN}$ and SSc(+) $18 \mathrm{MN}$ that were reexamined after discontinuing therapy. Dermoscopic changes persisted in $7 \mathrm{MN}$ [4 SSc (+); $3 \mathrm{SSc}(-)]$ and new dermoscopic changes (late onset) emerged in $2 \mathrm{MN}$ [2 SSc (+)] 3-6 months after the end of therapy. When the dermoscopic changes were considered separately, it was observed that most returned to their former state 
TABLE 2. More frequently observed dermoscopic changes in SSc(-) MN compared to $\mathrm{SSc}(+) \mathrm{MN}$ at the beginning vs. end of NBUVB therapy*** $(n=120)$

\begin{tabular}{|c|c|c|c|}
\hline & SSc(+); n (\%) & SSc(-); n (\%) & $\mathbf{P}$ \\
\hline Decrease in size & $5(9.6 \%)$ & $23(33.8 \%)$ & $=0.04$ \\
\hline Symmetric & 5 & 19 & \multirow{2}{*}{$>0.05$} \\
\hline Asymmetric & 0 & 4 & \\
\hline Loss of construction & $2(3.8 \%)$ & $13(19.1 \%)$ & $=0.026$ \\
\hline Loss of pigment network & 2 & 11 & \multirow{3}{*}{$>0.05$} \\
\hline Dots/globules & 0 & 1 & \\
\hline Branched streaks & 0 & 1 & \\
\hline Fading in pigmentation & $19(34.6 \%)$ & $33(47.1 \%)$ & $\mathrm{p}>0.05$ \\
\hline Symmetric-homogeneous & 17 & 30 & \multirow{4}{*}{$>0.05$} \\
\hline Asymmetric & 0 & 2 & \\
\hline Central & 2 & 0 & \\
\hline Peripheral & 0 & 1 & \\
\hline Fading in pigment network & $11(21.2 \%)$ & $19(27.9 \%)$ & $p>0.05$ \\
\hline Symmetric-homogeneous & 11 & 19 & NA \\
\hline New structure formation & $1(1.9 \%)$ & $6(8.8 \%)$ & $\mathrm{p}>0.05$ \\
\hline Pigment network & 0 & 3 & \multirow{7}{*}{ NA } \\
\hline Streaks & 0 & 1 & \\
\hline Dot-globul & 0 & 1 & \\
\hline White scar-like Depigmentation & 1 & 1 & \\
\hline Structureless areas & 1 & 0 & \\
\hline Ulcer & 1 & 0 & \\
\hline Chrysalis structures & 1 & 0 & \\
\hline New color formation & $1(\% 1.9 \%)$ & $4(5.9 \%)$ & $\mathrm{p}>0.05$ \\
\hline Blue & 0 & 1 & \multirow{3}{*}{ NA } \\
\hline White & 1 & 1 & \\
\hline Blue-gray & 0 & 2 & \\
\hline Loss of color & $0(0 \%)$ & $1(1,5 \%)$ & NA \\
\hline Black & 0 & 1 & NA \\
\hline Increase of dots-globules & $1(1.9 \%)$ & $1(1.5 \%)$ & NA \\
\hline
\end{tabular}

${ }^{\star} \mathrm{NA}=$ No Analysis

${ }^{* *}$ The above given MN and the dermoscopic parameter numbers do not match, because more than one dermoscopic parameter was observed in one MN.

or had a tendency to do so (Table 4, Figure 2). The dermoscopic changes and histopathologic results of excised $\mathrm{MN}$ are summarized in Table 5.

Before starting the study, it was calculated with $80 \%$ power that $95 \%$ confidence could be achieved if $49 \mathrm{MN}$ would be included in each group (at least $98 \mathrm{MN}$ ) when power analysis had been performed, assuming the obtainable ratios would be $10 \%$ and $30 \%$. When the results of the study were examined, power analysis was performed according to these results [for size decrease $\mathrm{SSc}(+)$ 9.6\% vs SSC(-) $33.8 \%$, and for structure loss SSC(+) $3.8 \%$ vs. SSC(-) $19.1 \%$ ], and it was determined that the present study had $95 \%$ and $86 \%$ power, respectively, with $95 \%$ confidence.

\section{Discussion}

Prevelance of $\mathrm{MN}$ changes according to age, genetic and environmental factors, and the number of $\mathrm{MN}$, which are low in childhood can increase in time [10]. The most studied enviromental factor in terms of relevance with $\mathrm{MN}$ development is UV light. An animal model demonstrated that UVB and UVA2 both induce MN development [11,12]. Epidemiological and twin studies revealed a relationship between the number of $\mathrm{MN}$ and the intermittant intense UV exposure; however, no relationship was established between daily UV exposure and MN number $[13,14]$. It was shown that as the experienced sunburn number and severity increase, new $\mathrm{MN}$ 
TABLE 3. More frequently observed dermoscopic changes in $\mathrm{SSc}(+) \mathrm{MN}$ compared to $\mathrm{SSc}(-) \mathrm{MN}$ at the beginning vs. at the end of NBUVB therapy $(n=120)$

\begin{tabular}{|c|c|c|c|}
\hline & SSc(+); n (\%) & SSc(-); n (\%) & $\mathbf{P} *$ \\
\hline Increase in size & $3(5.8 \%)$ & $3(4.4 \%)$ & $\mathrm{p}>0.05$ \\
\hline Symmetric & 2 & 3 & NA \\
\hline Asymmetric & 1 & 0 & \\
\hline Darkening in pigmentation & $4(7.7 \%)$ & $4(5.9 \%)$ & $\mathrm{p}>0.05$ \\
\hline Symmetric -homogenous & 4 & 4 & NA \\
\hline Darkening in pigment network & $4(7.7 \%)$ & $2(2.9 \%)$ & $\mathrm{p}>0.05$ \\
\hline Symmetric-homogenous & 4 & 2 & NA \\
\hline Decrease in the number of dots/globules & $4(7.7 \%)$ & $4(5.9 \%)$ & $\mathrm{p}>0.05$ \\
\hline
\end{tabular}

${ }^{\star} \mathrm{NA}=$ No Analysis

TABLE 4. The course of dermoscopic changes 3-6 months after end of therapy*

\begin{tabular}{|l|c|c|c|} 
& $\begin{array}{c}\text { Returned to the original } \\
\text { state or tended to do so }\end{array}$ & Persisted or progressed & Late onset \\
\hline Increase in size & $9.5[4.6: 4.6]$ & $2.3[2.3: 0]$ & $4.6[2.3: 2.3]$ \\
\hline Decrease in size & $21.4[0: 21.4]$ & $4.6[2.3: 2.3]$ & $2.3[2.3: 0]$ \\
\hline Darkening in pigmentation & $9.5[4.6: 4.6]$ & $4.6[4.6: 0]$ & 0 \\
\hline Fading in pigmentation & $28.5[6.9: 21.4]$ & $11.9[4.6: 6.9]$ & $4.6(4.6: 0]$ \\
\hline $\begin{array}{l}\text { Darkening in pigment } \\
\text { network }\end{array}$ & $9.5[4.6: 4.6]$ & $2.3[2.3: 0]$ & 0 \\
\hline Fading in pigment network & $16.6[4.6: 11.9]$ & $9.5[2.3: 6.9]$ & 0 \\
\hline New structure development & $6.9[2.3: 4.6]$ & $2.3[0: 2.3]$ & $2.6[2.3: 2.3]$ \\
\hline Loss of structure & $14.2[2.3: 11.9]$ & $2.3[0: 2,3]$ & $2.3[0: 2.3]$ \\
\hline $\begin{array}{l}\text { Increase in the number of } \\
\text { dots/globules }\end{array}$ & 0 & $2.3[2.3: 0]$ & $0]$ \\
\hline $\begin{array}{l}\text { Decrease in the number of } \\
\text { dots/globules }\end{array}$ & $6.9[2.3: 4.6]$ & $2.3[2.3: 0]$ & 0 \\
\hline New color development & $2.3[0: 2.3]$ & 0 & 0 \\
\hline Loss of color & $2.3[0: 2.3]$ & 0 & 0 \\
\hline
\end{tabular}

*\%total [\%SSc(+): \%SSc(-)]; these ratios were calculated within $42 \mathrm{MN}$ that were reexamined after discontinuing therapy

development increases [15]. These findings explain that the nevogenic effect of UV is dose dependent and is distinctive in areas where environmental UV is much more intense. We did not observe new MN development in our study. It can be related to other factors, including that almost all our patients were dark phenotype, all were over 18 years old, and we had short-term follow-up. In addition, the ones who had severe sunburn history were excluded from the study, and during treatment the UV dosage were raised gradually. There are genetic factors that have not been identified, yet might have a role.

UV light can cause clinical, histopathologic and dermoscopic changes in MN by increasing melanin synthesis or inducing melanocyte proliferation [3-5]. Dermoscopic changes were reported in $27-50 \%$ of $\mathrm{MN}$ during NBUVB treatment $[16,17]$ and even in $43.2 \%$ of covered $\mathrm{MN}$ during psoralen-ultraviolet A (PUVA) and NBUVB treatment [7]. We observed dermoscopic changes in most of the $\mathrm{MN}$ $(65 \%)$ despite being covered with opaque tape in all and with SSc in half of them. Higher ratios that are found in our study may be related to the detailed dermoscopic evaluation parameters.

Lin et al recognized size changes in a larger proportion of the MN located on the abdominal region in comparison to the MN located on other body sites but noted no significant relation with skin type [16]. In our study, we did not detect any differences in dermoscopic changes between $\mathrm{SSc}(+)$ and SSc(-) MN groups according to anatomical location.

Kılınç Karaaslan et al observed increase in size in uncovered MN but not in opaque tape-covered $\mathrm{MN}$ at the end of 


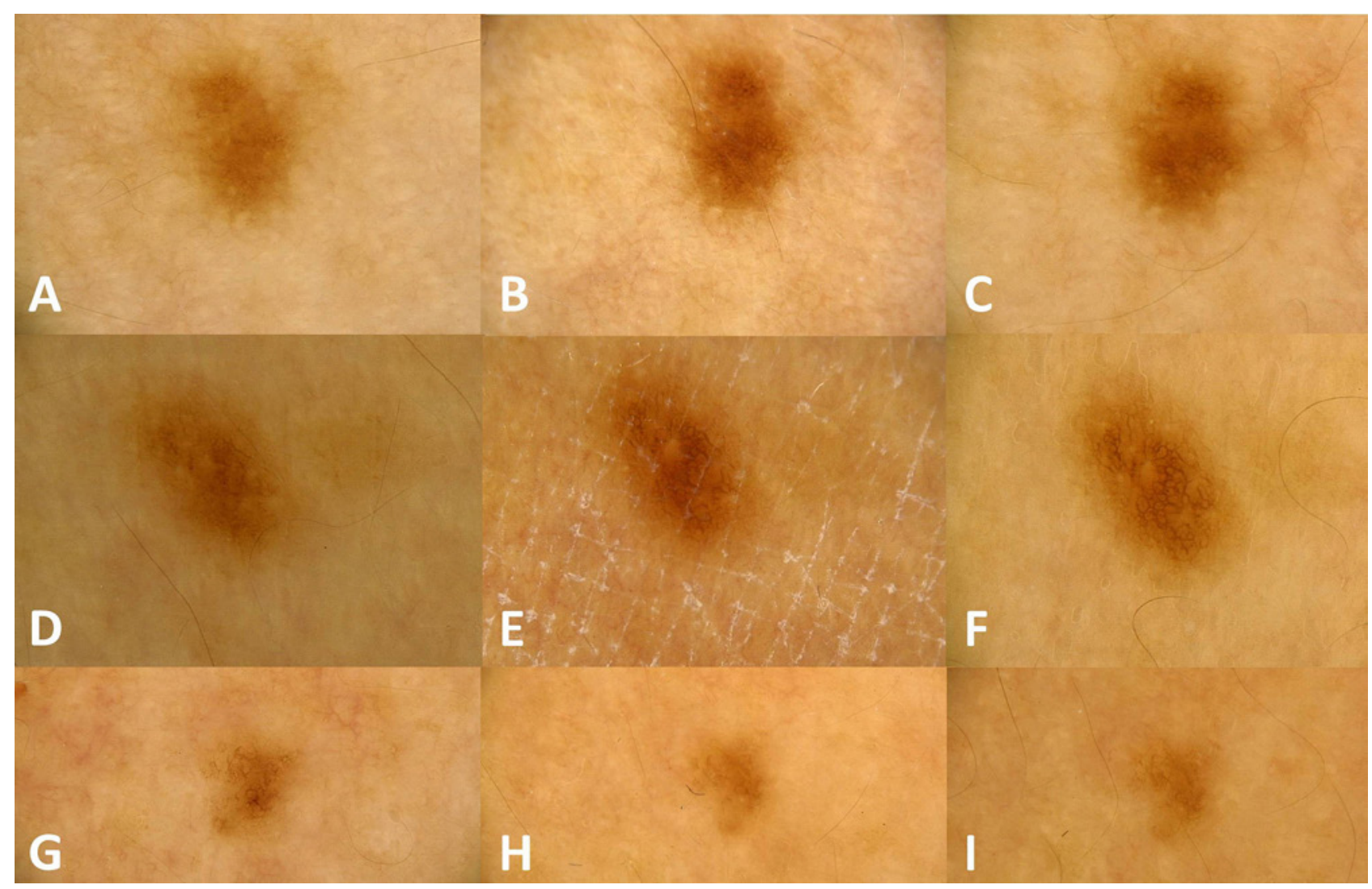

Figure 2. Darkening in pigmentation and pigment network (B, E) and fading in pigmentation and pigment network $(\mathrm{H})$ at the end of therapy compared to the beginning $(\mathrm{A}, \mathrm{D}, \mathrm{G})$ in three $\mathrm{MN}$. It is seen that dermoscopic changes showing tendency to return back $(\mathrm{C})$, increasing (F) and persisting (I) 3-6 months after the end of therapy. [Copyright: @2018 Ök Kekeç et al.]

TABLE 5. Dermoscopic changes in excised MN

\begin{tabular}{|l|c|c|c|c|}
\hline \multicolumn{1}{|c|}{ Dermoscopic changes } & MN1 & MN2 & MN3 & MN4 \\
\hline Structureless areas & + & - & - & - \\
\hline Ulcer & + & - & - & - \\
\hline Chrysalis structures & + & - & - & + \\
\hline Streaks formation & - & + & - & - \\
\hline White scar-like depigmentation & + & + & + & - \\
\hline Decrease in size & - & - & - & + \\
\hline Increase in size & - & + & + & + \\
\hline Fading in pigmentation & - & - & - & + \\
\hline Darkening in pigmentation & - & - & + & - \\
\hline Fading in pigment network & - & - & - & + \\
\hline Decrease in the number of dots/globules & - & + & - & - \\
\hline Loss of pigment network & Intradermal nevus & Junctional nevus & Junctional nevus & Dysplastic nevus \\
\hline Histopathologic diagnosis & & & \\
\hline
\end{tabular}

a mean 9 weeks of NBUVB treatment [8]. Similarly to their observation, Ghani-Nejad et al determined a significant increase in size in uncovered $\mathrm{MN}$, but not in opaque tapecovered MN, after NBUVB treatment for 30-60 sessions [7]. Contrary to these studies, Karaca et al established a statistically significant mean area measurement increase in $\mathrm{MN}$, despite being uncovered, in patient groups who received
NBUVB, UVA1 and PUVA treatments for three months [17]. None of the above studies mention decrease in size in $\mathrm{MN}$ and it was not stated whether size decrease was taken into consideration.

Lin et al detected size change in $40 \%$ of $\mathrm{MN}$ during NBUVB treatment, and similar to our study, they evaluated $\mathrm{MN}$ size in terms of both decrease and increase. They 
observed size decrease and increase in $54 \%$ and $46 \%$ of $\mathrm{MN}$ that displayed size change, respectively [16].

Dobrosavljevic et al evaluated dermoscopic changes in MN of patients using and not using SSc 28 days after UV exposure for a minimum of 7 days. They did not detect any significant change in $\mathrm{MN}$ in terms of size increase between the two groups. However, 28 days after the end of UV exposure they observed that the fading in pigmentation in a large proportion of $\mathrm{MN}$ belonged to the group that was not using SSc compared to other group who was using SSc (61.9\% vs. $20.5 \%$, respectively) [18].

In our study, we detected size change in the $27.5 \%$ of $\mathrm{MN}, 84.8 \%$ of which showed decrease in size. The ratios of MN that showed size decrease and structure loss were statistically significantly higher in the SSc(-) group compared to the $\mathrm{SSc}(+)$ group. In addition, we also found the ratios of $\mathrm{MN}$ that showed fading in pigmentation network and in pigmentation were also higher in the SSc(-) group, although the difference did not reach a statistically significant level. We excised one of the MN that showed size decrease, fading in pigmentation, and pigmentation network, but no other dermoscopic change, and we did not detect atypical histopathologicafindings. We thought that the above-mentioned dermoscopic findings might have emerged by induction of melanocyte apoptosis and blockage of melanin production from melanocytes by NBUVB [19,20]. According to our findings, it can be speculated that SSc application in combination with opaque tape may hinder the triggering effects of NBUVB over MN involution.

Hofmann-Wellenhof et al detected significant darkening in brown color and total irregularity generation in uncovered MN during UVB treatment but no significant dermoscopic changes in those covered by opaque tape. However, when considering $\mathrm{MN}$ covered and uncovered with opaque tape together, they recognized that $\mathrm{MN}$ showed significantly more "total irregularity," darker "brown color," and increase in brown globules and pigment network width at the end of UVB treatment compared to the beginning. In all, they thought these changes may depend on the systemic effects of UV radiation on $\mathrm{MN}$ [5]. The emergence of dermoscopic changes in the majority of MN during our study, despite being covered with opaque type, supports the systemic effects of UV on MN.

Kılınç Karaaslan et al established that the majority of dermoscopic changes arising after NBUVB and PUVA treatments were reversible [8]. Lin et al observed that while enlarged MN after NBUVB treatment tended to revert to pretreatment size 3 months after the cessation of therapy, the trend for $\mathrm{MN}$ showing size decrease was for continued size reduction [16].

The majority of dermoscopic changes occured in our study showed a tendency to return to their former state at approximately a mean of 4.2 months after cessation of
NBUVB exposure in both study groups. However, dermoscopic changes remained in some MN. In addition, dermoscopic changes emerged 3-6 months after the end therapy in some $\mathrm{MN}$ that did not show any dermoscopic changes at the end of therapy. Those dermoscopic changes can be due to lateonset or persistent effects of NBUVB but can also be related to the natural evolution of $\mathrm{MN}$, independent from NBUVB, as claimed by Dobrosavljevic et al. Long-term follow up studies may clarify this condition [18].

\section{Conclusion}

In conclusion, NBUVB treatment causse various dermoscopic changes in $\mathrm{MN}$; some of these changes can be prevented with opaque tape. SSc in combination with opaque tape helps in preventing the development of dermoscopic changes in $\mathrm{MN}$, including size decrease and structure loss.

\section{Acknowledgments}

This study was financially supported by grant number 2015TPF011 from the Scientific Research Projects Foundation of Pamukkale University. We thank Hande Şenol, Lecturer, for her help and comments in statistical analyses.

\section{References}

1. Sokolova A, Lee A, D Smith S. The safety and efficacy of narrow band ultraviolet $\mathrm{B}$ treatment in dermatology: a review. Am J Clin Dermatol. 2015;16(6):501-531.

2. Seebode C, Lehmann J, Emmert S. Photocarcinogenesis and Skin Cancer Prevention Strategies. Anticancer Res. 2016;36(3):13711378.

3. Hofmann-Wellenhof R, Soyer HP, et al. Ultraviolet radiation of melanocytic nevi: a dermoscopic study. Arch Dermatol. 1998;134(7):845-850.

4. Stanganelli I, Rafanelli S, Bucchi L. Seasonal prevalence of digital epiluminescence microscopy patterns in acquired melanocytic nevi. J Am Acad Dermatol. 1996;34(3):460-464.

5. Hofmann-Wellenhof R, Wolf P, Smolle J, Reimann-Weber A, Soyer HP, Kerl H. Influence of UVB therapy on dermoscopic features of acquired melanocytic nevi. J Am Acad Dermatol. 1997; 37(4):559-563.

6. Manganoni AM, Rossi MT, Sala R, et al. Dermoscopic, histological and immunohistochemical evaluation of cancerous features in acquired melanocytic nevi that have been repeatedly exposed to UVA or UVB. Exp Dermatol. 2011;21(2):86-90.

7. Ghani-Nejad H, Hallaji Z, Damavandi MR, et al. Dermoscopic changes of melanocytic nevi after psoralen-ultraviolet $A$ and narrow-band ultraviolet B phototherapy. Indian J Dermatol. 2016;61(1):118.

8. Kilinc Karaarslan I, Teban L, Dawid M, Tanew A, Kittler H. Changes in the dermoscopic appearance of melanocytic naevi after photochemotherapy or narrowband ultraviolet B phototherapy. J Eur Acad Dermatol Venereol. 2007;21(4):526-531. 
9. Akdeniz N. Fototerapinin yan etkileri ve kontrendikasyonları. In: Elçin G, Karadağ AS, Yılmaz E, eds. Fotodermatoloji. $1^{\text {st }}$ ed. Istanbul: Galenos Yayınevi. 2015:315-333.

10. Grichnik JM, Rhodes AR, Sober AJ. Benign neoplasias and hyperplasias of melanocytes. In: Wolff K, Goldsmith LA, Katz SI, Gilchrest BA, Paller AS, Leffell DJ, eds. Fitzpatrick's Dermatology in General Medicine. 7th ed. New York: McGraw-Hill. 2008:1099-1122.

11. Gallagher RP, Rivers JK, Lee TK, Bajdik CD, McLean DI, Coldman AJ. Broad-spectrum sunscreen use and the development of new nevi in white children: a randomized controlled trial. JAMA. 2000;283(22):2955-2960.

12. Menzies SW, Greenoak GE, Abeywardana CM, Crotty KA, O'Neill ME. UV light from 290 to $325 \mathrm{~nm}$, but not broad-band UVA or visible light augments the formation of melanocytic nevi in a guinea-pig model for human nevi. J Invest Dermatol. 2004;123(2):354-360.

13. Dulon M, Weichenthal M, Blettner M, et al. Sun exposure and number of nevi in 5- to 6-year-old European children. J Clin Epidemiol. 2002;55(11):1075-1081.
14. Wachsmuth RC, Turner F, Barrett JH, et al. The effect of sun exposure in determining nevus density in UK adolescent twins. J Invest Dermatol. 2005;124(1):56-62.

15. Harrison SL, MacLennan R, Buettner PG. Sun exposure and the incidence of melanocytic nevi in young Australian children. Cancer Epidemiol Biomarkers Prev. 2008;17(9):2318-2324.

16. Lin CY, Oakley A, Rademaker M, Hill S, Yung A. Effect of narrowband ultraviolet B phototherapy on melanocytic naevi. $\mathrm{Br} J$ Dermatol. 2013;168(4):815-819.

17. Karaca F, Öztaş M, Gürer MA. Effects of narrow band UVB, UVA1 and PUVA treatments on dermoscopic features of melanocytic nevi. Turkderm. 2014;48(1): 26-30.

18. Dobrosavljevic D, Brasanac D, Apostolovic M, Medenica L. Changes in common melanocytic naevi after intense sun exposure: digital dermoscopic study with a 1-year follow-up. Clin Exp Dermatol. 2009;34(6):672-678.

19. Terushkin V, Scope A, Hofmann-Wellenhof R, Marghoob A. Disappearance of Melanocytic Nevi. In: Marghoob A, ed. Nevogenesis. Verlag Berlin Heidelberg: Springer. 2012:145-153.

20. Kittler H. Evolution of nevi. In: Marghoob A, ed. Nevogenesis. Verlag Berlin Heidelberg: Springer. 2012:43-47. 